\title{
The Role of Financing in the Development of Human Capital of Mining Industry: Modern Trends under Uncertainty
}

\author{
Viktoriia Frolova ${ }^{1, *}$, Olga Dolina $^{1}$, and Tatyana Shpilkina ${ }^{2}$ \\ ${ }^{1}$ Financial University under the Government of the Russian Federation, 125993 Leningradsky av., \\ 49, Moscow, Russia \\ ${ }^{2}$ Moscow Automobile and Road Construction State Technical University (MADI), 125319 \\ Leningradsky av., 64, Moscow, Russia
}

\begin{abstract}
The authors studied financing issues in the development of human capital in mining industry. They analyzed the distribution of financial resources in the field under current conditions of the economic activity decrease at the enterprises in connection with the spread of coronavirus infection. An assessment of the demand for vacancies by profession, region and wage level was made. The issues of enterprise personnel management in the form of a set of interacting and interconnected HR-technologies that allow enterprises to manage the staff and work more efficiently are studied. The authors concluded that an important aspect of the quality personnel training and the development of modern companies is a properly built system of improving the quality of human capital, as well as, measures for ensuring safety and preserving health, improving the qualification level, creating conditions for creativity and labor potential growth.
\end{abstract}

\section{Introduction}

The global economy is undergoing significant changes due to the coronavirus pandemic. The benefits and costs of integration, global supply and distribution chains are being transformed into more local ones. The events of the last period were reflected in the processes of human capital development in mining companies. This is due, first, to a decline in production in the global economy, a decrease in demand for the products of mining enterprises, including Russian coal, as well as to the closure of border checkpoints and the stoppage of railway deliveries. Under the prevailing conditions, all mining, enriching and processing enterprises of our country have made it a priority to provide employees' health care and, if possible, to protect them from the threat of COVID-19 infection.

Under new conditions, companies are forced to redistribute financial resources to ensure the employees' health and safety. Mining companies transferred work as it is possible to the remote mode, tightened control over the employees' health, and invest financial resources in special equipment and personal protective equipment. They purchase special equipment and test systems. For example, the largest Russian gold mining company PJSC Polyus has

\footnotetext{
*Corresponding author: academy@,fa.ru
} 
acquired several thousand tests of Russian-Japanese production. They allow getting analysis results within half an hour, which makes them one of the fastest in the world [1].

One of the largest mining companies, United Company Rusal transferred the employees of the holding's central office to a remote working mode. Only those who work on a continuous operating equipment stayed in production process. In addition, the company invested in the construction of three infectious diseases hospitals in the Irkutsk region - in Bratsk, Taishet and Shelekhov - in those settlements where Rusala enterprises and its managing company En + are located [2].

Under the conditions of uncertainty in the global and Russian economies, taking into account the rapid development of digital technologies, the issues of personnel training and retraining and its constant development become relevant. In addition, the priorities in the existing structure of professions are changing rapidly. The labor market is rapidly transforming in the modern period, and this is due not only to the coronavirus pandemic, but also to the rapid development of the digital economy, the emergence of new technological ideas and processes, which also makes the labor market change. More and more often, employees with engineering, technical and economic education begin to be in demand. In the digital economy, they have priority over other professions.

For the development of the country's economy in the crisis and post-crisis periods, it is necessary to make maximum use of the capabilities of digital technologies, the available human and financial resources. A tremendous impact on the labor market is made by the development trends of modern world economy, which include the following:

- uneven economic development, both in territorial and temporal aspects;

- close attention to the implementation of innovations in all business processes;

- acceleration of environmental change processes;

- slowdown of the labor market globalization and international mobility of human resources.

\section{Materials and Methods}

Today, the leading mining companies use various management and processing structures for information resources to organize ongoing work. However, the use of advanced technologies requires a qualitatively different system of personnel training, focused on the use of various information resources. Practice shows that existing mechanisms have significant shortcomings, as they create new requirements for organizations, managers and engineering professions. An important principle is the principle of changing the traditional way of collecting and processing information through the implementation of Big Data (Big Data), which determines changes in training in the digital economy.

Accordingly, in recent years such professions as mining engineer, geologist, mine surveyor (a specialist working in the field of exploration and mining or in construction), mineworker (miner) and other mining professions have been in high demand in the labor market. So, according to data for mid-April 2020, in the Russian labor market such vacancies as geologists - 678; mine surveyors - 526; mining engineers - 285; mineworkers (miners) 743; blasting engineers - 285 are free [3]. The data are shown in Fig. 1. 


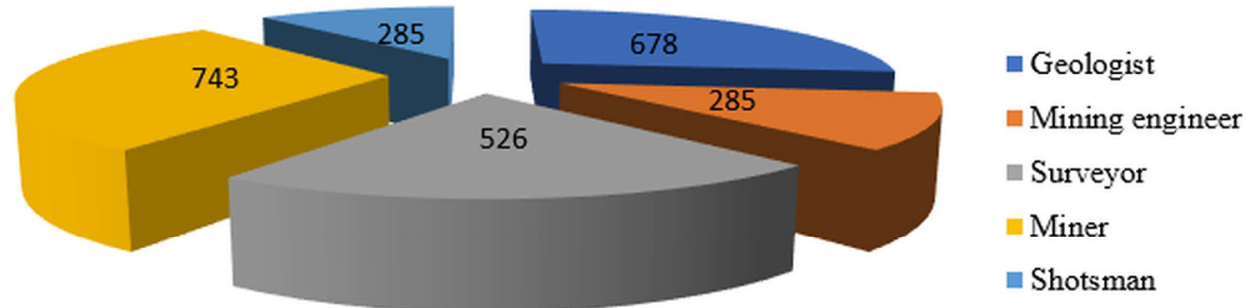

Fig. 1. Vacancies in the mining industry in the Russian Federation on 17. 04.2020.

As it can be seen from Fig. 1 most of all opening jobs are for mineworkers (miners) - over 700 people. In the second place are geologists (678 vacancies). This means that it is necessary to train personnel in these areas, and to train those who have lost their jobs or want to get a new profession, due to the lack of demand for the existing one.

Of course, the search for sources of financing for the development of education becomes important during this period. Thus, according to the authors V. Frolova, O. Dolina, T. Shpil'kina, budget financing of mining education in the conditions of limited budget funds is not able to ensure effective modernization of the industry [4]. In this regard, it is necessary to search and use additional sources of financing for mining education. The professional mining community is interested in searching for funds of non-state financing of educational institutions. To prepare high-quality specialists the part of their training cost will have to be provided by enterprises, private investors, and entrepreneurs.

No less important are the issues of personnel management and development. Human resource management in modern organizations solves many interrelated tasks and uses a combination of tools called HR technologies. For the effective solution of strategic and tactical tasks in the HR field, it is advisable to build personnel management as a modern technological process. The technological approach to HR management allows organizing personnel management at the enterprise in a set of interacting and interconnected HR technologies.

Under HR-technology researchers understand "a way of managing the quantitative and qualitative characteristics of the personnel or staff of an organization, ensuring the achievement of goals and the effectiveness of its functioning. Each HR technology is made up of smaller technologies. For example, recruitment technology includes staff searching and selection technologies. The selection technology, in turn, may include assessment center technology, interviews on behavioral examples, reference collection technology, and others.

Russian and foreign companies apply HR management technologies as part of a technological approach to human resource management, which has gained its popularity relatively recently. Of particular interest is the practice of applying HR technologies in multinational corporations (MNC), since here we can talk about a complete or partial mixture of Russian and foreign business practices. Moreover, it is MNCs that are often pioneers bringing modern, innovative, HR technologies along with their business to less developed countries. Accordingly, MNCs not only transfer HR technologies of the parent company to subsidiaries, but also are engaged in their assimilation and adaptation. At the same time, scientific research constantly emphasizes that a simple cross-border transfer of technology will not automatically enable it to be successfully implemented in a new country and new organization. Accordingly, there is a need for competent perception, fundamental analysis, subsequent adaptation and, possibly, even modification of Western HR technologies [5]. For the evolution of HR-technologies, an important role is played by MNCs and their HRservices. The ability to implement successfully foreign HR technologies allows Russian enterprises to reach a new international level. 
Thus, the HR technologies used in a modern enterprise should be effective, i.e. they must have proven effectiveness in the area of personnel work in which they are supposed to be introduced. The criteria for the effectiveness of HR technology are as follows: focus on the problem, unification, adaptation and cost-effectiveness. In addition to the main criteria listed, the researchers also note the need for HR-technologies in information security and legal certainty, the presence of a clear relationship with the strategy and tactics of the company (personnel strategy and personnel policy, respectively).

\section{Results and Discussion}

A study conducted as a part of the analysis of the demand for professions in mining industry showed the following. In different regions of the country, the demand for professions in this field and wages vary depending on the enterprises located in this region and the availability of relevant personnel. For the analysis, we used data for the period from August 2019 to March 2020. The number of vacancies and the level of wages for professions and regions is different.

Consider the demand for the two most popular professions - these are mineworkers (miners) and geologists. Therefore, the miner has the largest number of vacancies in the profession in the Arkhangelsk region - 1680, in the second place is the Altai Territory with 1677 vacancies, in the third place is the Tula region, where 1634 vacancies are open. Such a demand for this type of profession is objective, since deposits are located in these regions and minerals are extracted. Open jobs for the geologist profession in the Russian Federation for 2020 are shown in Fig. 2.
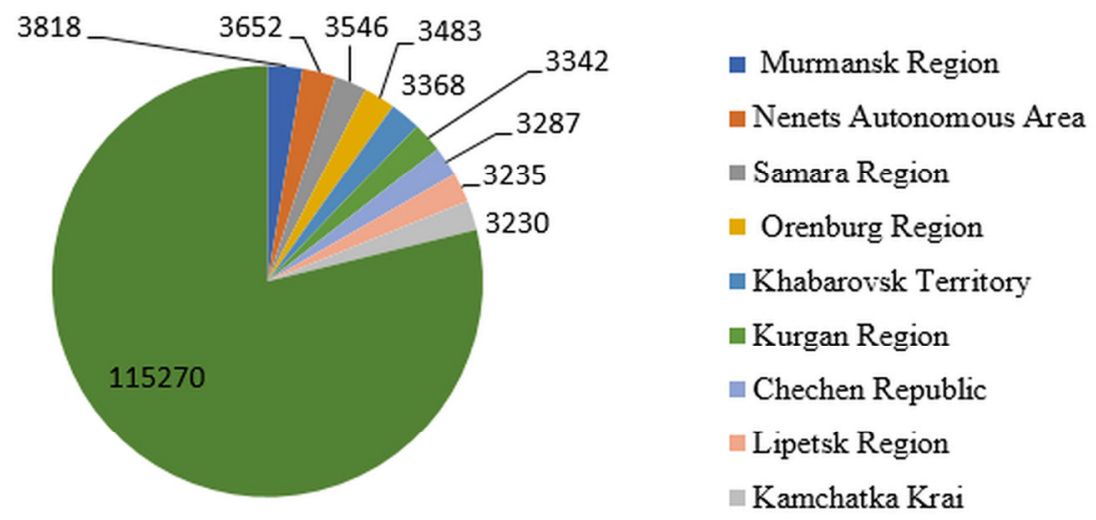

Fig. 2. Open jobs for the profession of geologist in the Russian Federation for 2020.

Fig. 2 shows that the geologist has the largest number of vacancies in the profession in the Murmansk region - 3818, the Nenets Autonomous Okrug is in second place, 3652 vacancies are open there, and Samara region with the number of vacancies 3546 is in the third place. In recent years, the Murmansk region has been developing despite difficult weather conditions and enterprises are being actively put into operation so there are not enough specialists for these vacancies.

Data on the level of wages by profession are shown in Fig. 3. It follows that in January 2020 the highest average level of wages was observed among specialists in the profession of mining engineer, namely 86,965 rubles. A surveyor comes next with an average level of remuneration in the amount of 82,470 rubles, in third place with an approximately equal level of payment, 74-75 thousand rubles is a miner, geologist and blasting engineer. As for March 2020 , the situation in terms of wages has worsened in almost all the professions represented. 
An average miner began to receive up to 55 thousand rubles, mining engineer - about 60 thousand rubles, and the level of remuneration of geologist and mine surveyor remained at about 74-75 thousand rubles. The salary level of blasting engineer has slightly increased, but it is also approximately at the level of 75 thousand rubles, like that of a geologist and mine surveyor.

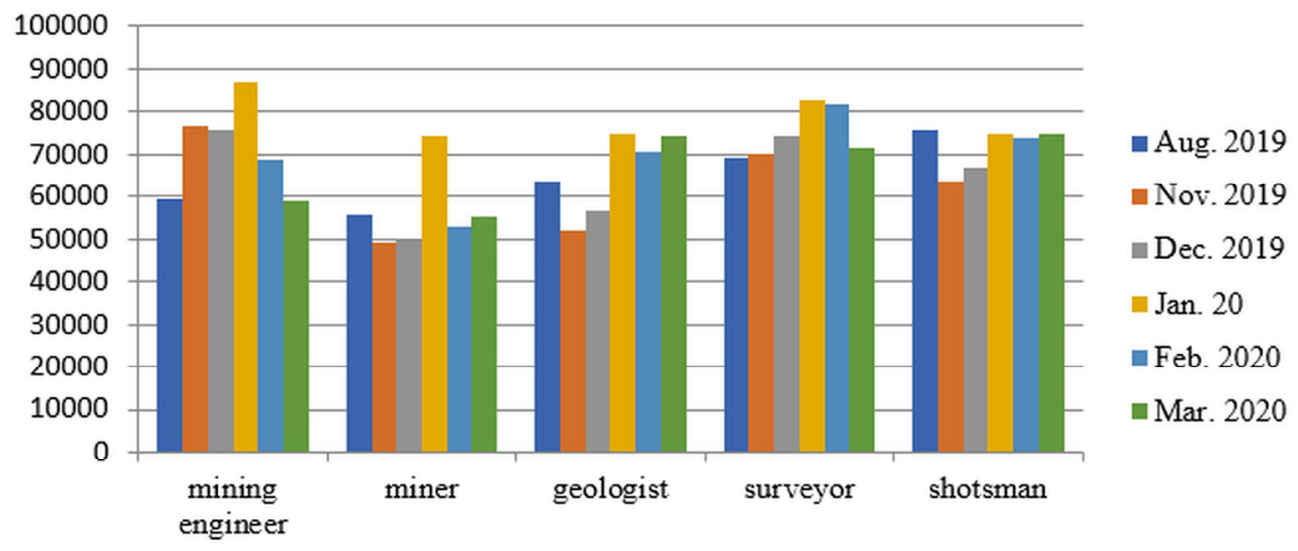

Fig. 3. The level of wages for mining professions in the Russian Federation for the period 08.2019-03.2020.

Obviously, wages are directly dependent on education, experience, and working period. However, at the beginning of 2020 the mining engineer and mine surveyor had the highest salary level. These professions require special training, knowledge and practical experience; in this regard, the level of remuneration was higher. However, a general deterioration in the economic situation led to a drop in wages for these categories of workers, but at the same time, the number of vacancies remains at a high level.

If for 5 years the majority of young people preferred such professions as programmer, economist, and financier when they entered universities then with the development of the digital economy and the problem of servicing equipment, it is specialists who receive an engineering education, as well as personnel who are ready to perform complex technical tasks are becoming of high demand. In this regard, the main modern trend in training is the concept of education and training professionals necessary for the digital economy, starting from school and throughout life. In accordance with this concept, in the framework of joint work, the students, teachers, heads of schools and other educational institutions, parents, politicians, academic experts, trade unions, as well as social and business partners developed the OECD Education-2030 project. In its work in various countries OECD Education-2030 identified several common problems, the overcoming of which is necessary for the training of a new employee. These problems include:

1. High workload of students - as a result students often do not have enough time to master key disciplinary concepts or, in the interests of a balanced life, to develop friendships, sleep and exercise. Under new conditions, online education and a combination of distance and traditional forms of learning have become widespread [6]; interactive forms of learning process are increasingly being implemented to improve the quality of training [7-12].

2. Curriculum reform suffers from time lags between recognition, decision-making, implementation and impact. There is a gap in the requirements of educational and professional standards. Obviously, careful planning is necessary as well as taking advantage of the digital economy. Priority should be given to knowledge, skills, approaches and values that can be learned in one context and shared with others. 
3. In the case of non-major education, for those wishing to work in new professions in mining industry, it is necessary to take appropriate retraining courses with a focus on mastering competencies and gaining practical experience. An important factor for the development of mining company is the continuity of generations, the exchange of experience, mentoring, especially at the initial stage of career development. Any experienced employee, a professional in his field, who has authority and influence, who will responsibly apply to the development of the ability of a young specialist and is ready to help him in mastering the profession and achieving goals, can be a mentor.

Summing up it should be noted that the prerogative requirements of the employer to the employees are knowledge, skills, experience in the profession, or the ability to train the profession in mining industry quickly.

\section{Conclusion}

Thus, taking into account the prevailing conditions for the development of the labor market and the education system, the following features and positive practices for the development of human capital in mining industry should be noted:

- redistribution of financial resources in mining companies in the direction of solving current problems related to ensuring the safety and health of workers (purchase of protective equipment and preventive measures, testing personnel working at the enterprises on a rotational basis for the presence of a virus; eliminating the inflow of external workers into brigades, etc.);

- additional transportation costs, an increase in the cost of delivering employees to the production sites with special buses with distance marking, for visual information materials;

- the use of digital technologies to organize a training system, advanced training and retraining, expert webinars for managers and employees in the development of new advanced technologies;

- transition to cascading digital communications in the organization's management system, starting from the top management level to the first-line one;

- the organization of online sports and cultural events, online training, regular physical training for employees, the development of digital channels for training and remote leisure;

- financing the development of social charity and corporate volunteering in the regions (the experience of Norilsk Nickel, RUSAL, PhosAgro and others) to provide the population and medical staff with protective masks and suits, rapid tests, artificial lung ventilation, ambulances, assistance to elderly people and people at risk, participation in donor campaigns, etc.

Along with the positive experience in the development of human capital in modern conditions, the following problems should be noted:

- the lack of understanding of individual workers of the necessity to work in new conditions, taking into account new requirements and limitations, even though industrial companies are strategic and system-forming enterprises with a continuous production cycle;

- the lack of skills of the management staff to organize work in a remote mode, to respond quickly to changing situations and maneuver financial resources;

- insufficient understanding by managers of the advantages of digital technologies for the modernization of the education system, advanced training and retraining in the crisis and post-crisis periods.

In conclusion, it should be noted that an important aspect of the quality training of personnel and the development of modern mining companies is a properly built system for improving the quality of human capital, including measures to ensure safety and preserve health, improve the qualification level, create conditions for creativity and labor potential growth. Presented HR-technologies of personnel management used in Russian and foreign 
companies, as well as mentoring mechanisms in enterprises, are undoubtedly important for improving the qualification level of personnel, increasing the professionalism of workers in this field and for developing the companies themselves.

\section{References}

1. Polus Public Company Web Site. URL: https://www.polyus.com/

2. RUSAL Holding Company Web Site. URL: https://rusal.ru/

3. Jobs in Russia: Current Jobs in Russia. URL:https://russia.trud.com

4. V. Frolova, O. Dolina, T. Shpil'kina, E3S Web Conf., 21, 04018 (2017)

5. V.A. Maisel, E.P. Stepanenko, Young Scientist, 9, 639-644 (2016)

6. O. V. Borisova, V. B. Frolova, Recommendations for improving the process of training students in financial disciplines (LLC Delo, Moscow, 2016)

7. O. Kalenov, S. Kukushkin, R. Kamanina, E3S Web Conf., 105, 04028 (2019)

8. S. Kukushkin, O.Kalenov, E3S Web Conf., 105, 04022 (2019)

9. O. Miliushenko, A. Kovalev, M. Zhidkova, E3S Web Conf., 105, 04046 (2019)

10. M. Anastasov, N. Kazitskaya, I. Politkovskaya, E3S Web Conf., 105, 04043 (2019)

11. E. Dotsenko, N. Ezdina, E3S Web of Conf., 41, 04048 (2018)

12. T. Skryl, E. Shavina, E. Dotsenko, $\quad$ E3S Web Conf., 105, 04049 (2019) 